\title{
Air-Turbine with Self-Pitch-Controlled Blades for Wave Energy Conversion (Estimation of Performances in Periodically Oscillating Flow)
}

\author{
T. SETOGUCHI ${ }^{\mathrm{a}, *}$, S. RAGHUNATHAN ${ }^{\mathrm{b}}, \mathrm{M}^{\mathrm{M}}$ TAKAO $^{\mathrm{a}}$ and K. KANEKO ${ }^{\mathrm{a}}$ \\ a Department of Mechanical Engineering, Saga University, 1 Honjo-Machi, Saga-shi, Saga 840, Japan; \\ ${ }^{\mathrm{b}}$ Department of Aeronautical Engineering. The Queen's University of Belfast, Belfast, Northern Ireland, UK
}

(Received 23 May 1997; In final form 25 May 1997)

\begin{abstract}
In the development of an air-turbine with self-pitch-controlled blades for wave energy conversion, existence of hysteretic characteristics in a reciprocating flow has been examined. In order to clarify the validity of the analysis, a numerical simulation has been made by use of the experimental results obtained from a steady unidirectional flow condition. The comparison between the analysis and experiment has shown that the quasi-steady analysis is reasonable accurate for predicting the performance. The running and starting characteristics have also been investigated analytically taking into account the blade turning process during pitch.
\end{abstract}

Keywords: Fluid machinery, Natural energy, Wave power, Air-turbine, Self-pitch-controlled blades, Quasi-steady analysis

\section{INTRODUCTION}

In 1976, Dr. A.A. Wells proposed a form of selfrectifying axial flow air turbine, that is so-called Wells turbine, as a device suitable for wave energy conversion in oscillating water column (O.W.C.). There are several reports which investigate the performance of the Wells turbine both on the starting and running characteristics (Inoue et al., 1986a,b; Raghunathan et al., 1987). According to these results, the Wells turbine has inherent disadvantages, lower efficiency, poorer starting character- istics and higher axial thrust in comparison with conventional turbine.

In order to overcome these disadvantages, an airturbine with self-pitch-controlled blades for wave energy conversion shown in Fig. 1 was proposed (Inoue et al., 1989). The air turbine consists of several symmetrical airfoil blades which change by themselves the setting angles so as to obtain higher torque in a reciprocating airfoil. In Inoue et al. (1989), the experimental investigations were performed by model test of the rotor with fixed staggered blades under steady operating conditions.

\footnotetext{
* Corresponding author. Tel.: +81-952-28-8605. Fax: +81-952-28-8589.
} 


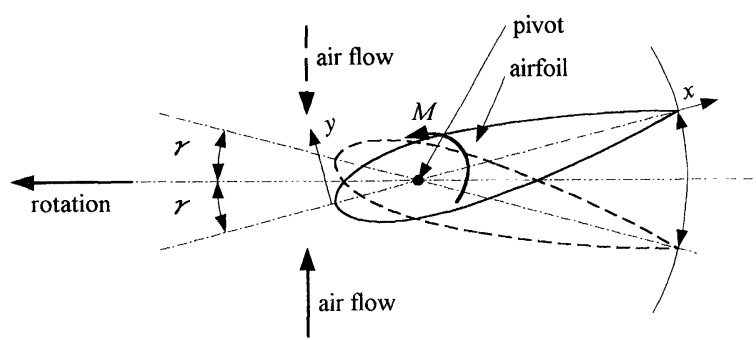

FIGURE 1 Air turbine with self-pitch-controlled blades.

The results have been shown that the turbine with self-pitch-controlled blades is superior to the Wells turbine both in the starting and running characteristics. However there are many unknown aspects. These are (i) the blades can set themselves automatically in a bidirectional air flow and (ii) the quasi-steady analysis is accurate for predicting the performance.

The objective of this paper is to present the design for a new air-turbine with self-pitch-controlled blades for wave energy conversion. In this report, the existence of hysteretic characteristics in a reciprocating flow has been examined. In order to clarify the usefulness of the analysis, a numerical simulation has been made by use of the experimental results obtained from a steady unidirectional flow condition. Furthermore, the running and starting characteristics has been investigated analytically taking into account the blade turning process.

\section{ANALYSIS OF UNSTEADY RUNNING CHARACTERISTICS}

Here we assume that the unsteady characteristics of an air-turbine with self-pitch-controlled blade can be estimated on the basis of experimental results obtained by the model testing of rotor with fixed turbine blade under steady unidirectional flow conditions.

For small setting angles $\left(\gamma<6^{\circ}\right)$ and low frequencies it may be assumed that the dynamic effects are small. Further the mutual interferences of blades due to pitching motion in a cascade are also neglected in the analysis.

Figure 2 shows the turbine characteristics for rotor with fixed setting angle (NACA0020, 6 blades) obtained under steady flow conditions (Inoue $e t$ al., 1989). In the figure, a doubly dotted-dash line $\left(\gamma=0^{\circ}\right)$ shows the $C_{T}$ and $C_{A}$ for Wells turbine. The running characteristics of the turbine is evaluated with a mean turbine efficiency for sinusoidal wave $\bar{\eta}$, which will be defined later. $\bar{\eta}$ for $\gamma \neq 0^{\circ}$, which calculated using the steady characteristics of Wells turbine $\left(\gamma=0^{\circ}\right)$, increases with $\gamma$. However we focus our attention on $\gamma \leq 6^{\circ}$ because the maximum mean efficiency was obtained in case of $\gamma \doteqdot 6^{\circ}$ under irregular flow conditions (Inoue et al., 1989).

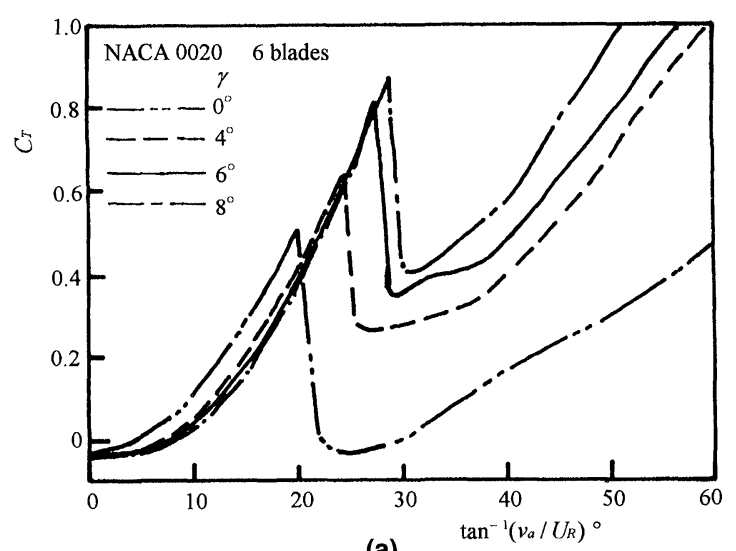

(a)

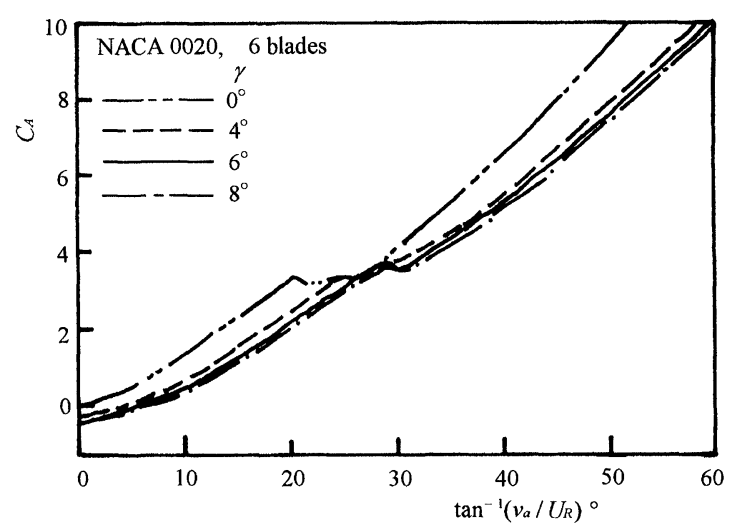

(b)

FIGURE 2 Turbine characteristics under steady flow conditions: (a) torque coefficient; (b) input coefficient. 


\section{TEST APPARATUS AND PROCEDURE}

The experiments were conducted by model tests of turbine rotor with fixed staggered blades under oscillating flow conditions.

The performance test of the turbine was carried out by use of newly devised wind tunnel in which it is possible to produce oscillating air flow by controlling the motion of a $1.4 \mathrm{~m}$ dia. piston in the cylinder as instructed by a micro-computer. The details are shown in Inoue et al. (1986b) and Setoguchi et al. (1990). In the test of turbine characteristics, the variations of turbine performance with relative inlet angle were examined by changing the rotational speed of rotor so as to cover the effective operating range of the turbine. During the test, the turbine output torque, the air-flow rate and the total pressure drop across the rotor were also measured. The uncertainty of mean efficiency is about $\pm 2 \%$.

Two kinds of rotors were selected for the experiments, that is, NACA0020 (6 blades) with chord length $l=90 \mathrm{~mm}$ for performance tests and NACA0015 (6 blades) with $l=90 \mathrm{~mm}$ for pressure measurements along blade surface. Other geometrical parameters of the turbine are as follows; hubto-tip ratio: 0.7 , tip diameter: $0.3 \mathrm{~m}$, tip clearance: $1 \mathrm{~mm}$. The Reynolds number of the experiments was $2.0 \times 10^{5}$.

\section{ANALYSIS OF RESULTS AND DISCUSSIONS}

\section{Quasi-Steady Analysis}

The equation of motion for a rotating system of the turbine with self-pitch-controlled blades is written in a nondimensional form as follows (Inoue et al., 1986a):

$$
S^{2} X_{I}\left(\mathrm{~d} \omega^{*} / \mathrm{d} t^{*}\right)+X_{\mathrm{L}}=F\left(\omega^{*}, t^{*}\right) .
$$

The nondimensional torque $F$ on the right side of Eq. (1) is expressed as

$$
F=z b l C_{T}\left(v_{\mathrm{a}} / V_{\mathrm{a}}\right)^{2} /\left(2 \pi R^{2} \sin ^{2} \alpha\right) .
$$

When the turbine is in the running conditions, the parameters of turbine performance such as $T_{\mathrm{L}}, \omega, \Delta p_{0}, Q$ vary periodically in a sinusoidally oscillating flow. In this case, turbine performances are indicated by mean values. The mean output is expressed as

$$
\overline{\overline{T_{\mathrm{L}} \omega}}=\overline{\overline{X_{\mathrm{L}} \omega^{*}}} \pi \rho V_{\mathrm{a}}^{2} R^{3} f,
$$

where $=$ denotes an average value over a period of wave motion. In the case that the turbine is controlled at a constant rotating speed, the value of $\overline{\overline{X_{\mathrm{L}} \omega^{*}}}$ is given from Eq. (1) as follows:

$$
\overline{\overline{X_{\mathrm{L}} \omega^{*}}}=\overline{\overline{X_{\mathrm{L}}}} \omega^{*}=\omega^{*} \int_{0}^{1} F\left(t^{*}\right) \mathrm{d} t^{*}=\overline{\bar{F}} \omega^{*}
$$

In the case of constant loading torque,

$$
\overline{\overline{X_{\mathrm{L}} \omega^{*}}}=X_{\mathrm{L}} \overline{\overline{\omega^{*}}} .
$$

The mean turbine efficiency is defined as

$$
\bar{\eta}=\overline{\overline{T_{\mathrm{L}} \omega}} / \overline{\overline{\Delta p_{0} Q}},
$$

where $\overline{\overline{\Delta p_{0} Q}}$ is given by the following relation:

$$
\overline{\overline{\Delta p_{0} Q}}=(\rho / 2) b l z V_{\mathrm{a}}^{3} \int_{0}^{1}\left\{C_{A}\left(v_{\mathrm{a}} / V_{\mathrm{a}}\right)^{3} / \sin ^{2} \alpha\right\} \mathrm{d} t^{*} .
$$

Figure 3 shows the turbine efficiency $\bar{\eta}$ against $V_{\mathrm{a}} /$ $U_{R}$ under sinusoidal flow condition. The experimental data from the oscillating flow tests agree well with the predictions based on unidirectional flow tests and quasi-steady assumptions.

The ratio of analytical and experimental maximum mean efficiency $\bar{\eta}_{\mathrm{m}_{\mathrm{t}}} / \bar{\eta}_{\mathrm{m}_{\mathrm{e}}}(>1)$ decreases with increasing $\gamma$ up to $\gamma=2^{\circ}$, subsequent to which the effect of $\gamma$ on $\bar{\eta}_{\mathrm{m}_{\mathrm{t}}} / \bar{\eta}_{\mathrm{m}_{\mathrm{e}}}(\doteqdot 1)$ is negligible. This phenomenon may be explained as follows. The effect of hysteresis on the performance is pronounced in the range of small setting angles as found in Wells turbine (Setoguchi et al., 1990). But, at larger setting angles, there exists little influence 


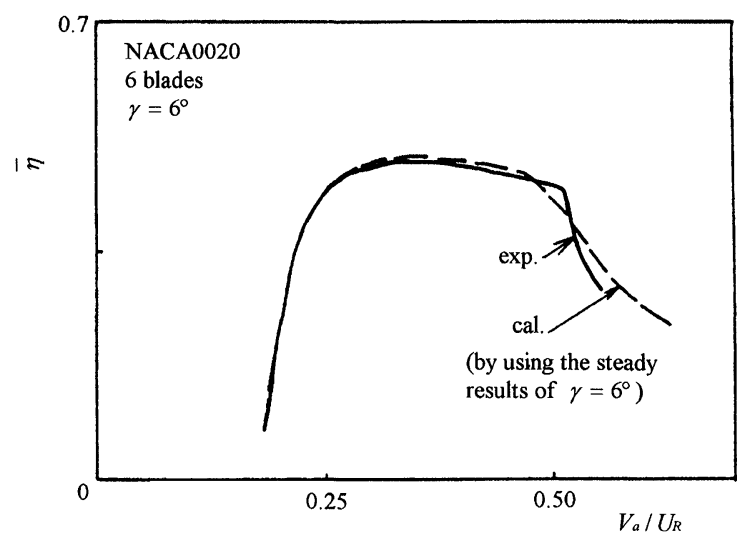

FIGURE 3 Comparison between calculated and measured mean efficiency.

on it because a wake-blade interaction diminishes. It is also clarified from Fig. 4, where the variation of $C_{A}$ is shown against relative inlet angle $\tan ^{-1}\left(v_{\mathrm{a}} /\right.$ $\left.U_{R}\right)$. The existence of large hysteresis is confirmed in the case of $\gamma=0^{\circ}$ compared with that of $\gamma=6^{\circ}$.

\section{Unsteady Characteristics Taking into Account the Blade Turning Process during Pitch}

So far, we assumed, for simplicity, that there is no delay in the behavior of turbine blade, namely, it turns instantaneously to the required setting angle corresponding to the flow direction. But, in practice, there appears the delay in the behavior of turbine blade because of the frictional torque of pivot. Therefore, to show the data about pitching moment of blade induced by air flow is very important from the viewpoint of not only the design of variable pitch mechanism but also the estimation of performance under actual situation.

The pressure distribution was measured along the rotating blade surface at the mean radius. The measuring system is shown in detail in Setoguchi et al. (1990). The typical example of pressure distribution of rotor with $\gamma=0^{\circ}$ is shown in Fig. 5, where $C_{p}$ is the pressure coefficient. It is clear that, on the suction side, there is a dip in the pressure distribution. This may be due to the fact that the wake from an upstream blade interacts with a downstream blade (Setoguchi et al., 1990).

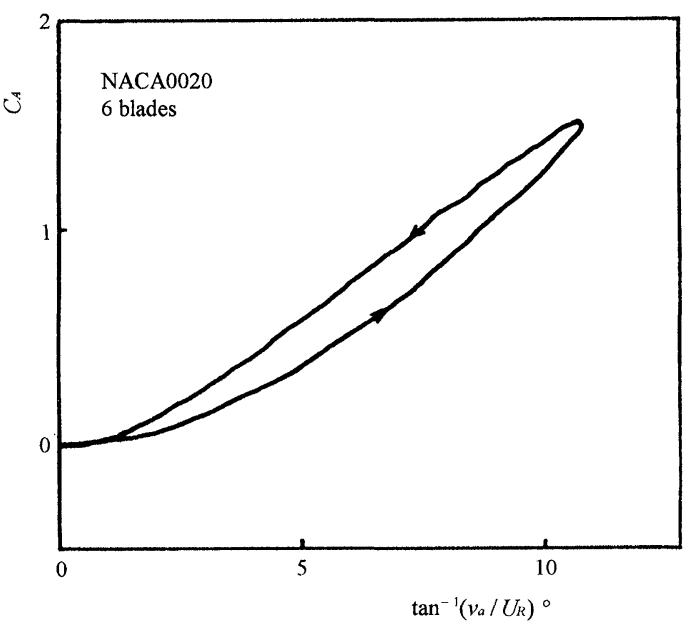

(a)

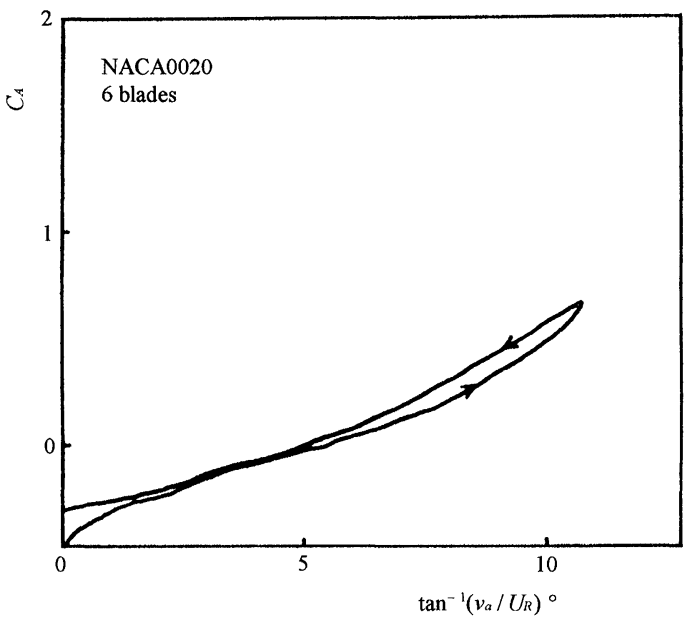

(b)

FIGURE 4 Hysteretic characteristics of input coefficient: (a) $\gamma=0^{\circ}$; (b) $\gamma=6^{\circ}$

The pitching moment around a pivot $M(>0)$ shown in Fig. 1 may be calculated from the pressure distribution. Figure 6 shows the relation between the pitching moment coefficient $C_{M}$ at various points along the chord $(x / l)_{p}$ and relative inlet angle. The figure shows that $C_{M}$ increases with $\tan ^{-1}\left(v_{\mathrm{a}} / U_{R}\right)$ for $(x / l)_{p}<0.3$. On the other hand, it becomes negative value for $(x / l)_{p}=0.4$. This means that the effective pivot position should be set at $(x / l)_{p}<0.3$, and the turning process of rotor blade becomes easier for smaller $(x / l)_{p}$. 


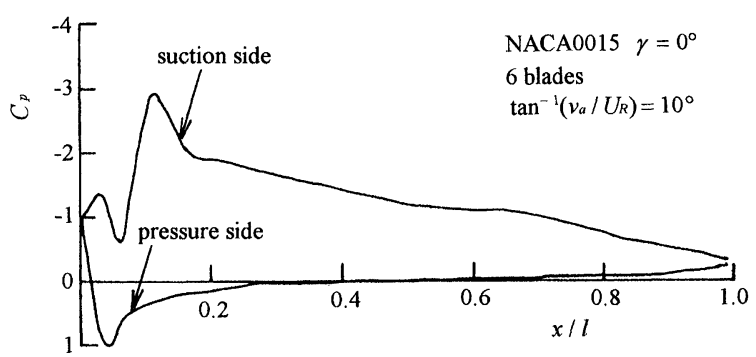

FIGURE 5 Pressure distribution along blade surface.

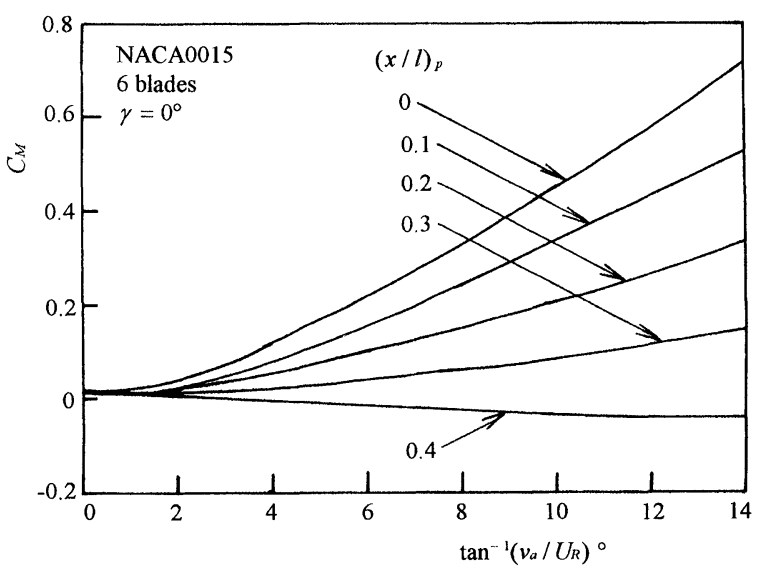

FIGURE 6 Effect of pivot position along blade chord on moment induced by air flow around airfoil.

The calculations of $\bar{\eta}$ were carried out taking into account the blade turning process. Namely, we assume that the blade turning begins at a certain value of relative inlet angle. We call it here minimum relative inlet angle $\left[\tan ^{-1}\left(v_{\mathrm{a}} / U_{R}\right)^{\circ}\right]_{d}$. In the calculation, we assume that the steady characteristics of $\gamma=0^{\circ}$ are available for $\tan ^{-1}\left(v_{\mathrm{a}} / U_{R}\right)<\left[\tan ^{-1}\left(v_{\mathrm{a}} /\right.\right.$ $\left.\left.U_{R}\right)\right]_{d}$ and those of $\gamma=\gamma^{\circ}$ for $\tan ^{-1}\left(v_{\mathrm{a}} / U_{R}\right)>$ $\left[\tan ^{-1}\left(v_{\mathrm{a}} / U_{R}\right)^{\circ}\right]_{d}$. There was no marked effect of turning process on $\bar{\eta}$.

In order to examine the effect of the blade turning process on the starting characteristics, the equation of motion (1) was solved numerically as an initial value problem. Typical example of the starting characteristics is shown in Fig. 7, where the broken and solid line denote the cases without and with taking into account the blade turning process, respectively, and the dotted-dash line is for Wells

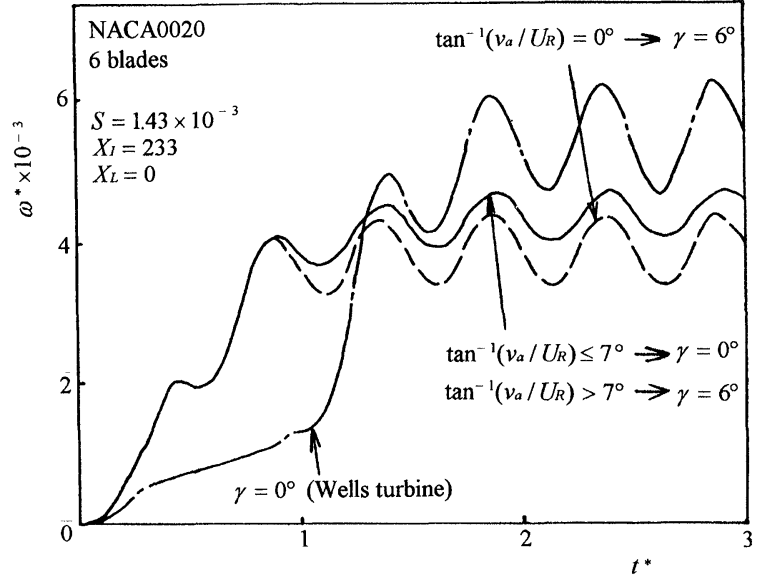

FIGURE 7 Starting characteristics taking into account of blade turning process.

turbine. As is evident from the figure, the air turbine with self-pitch-controlled blades is advantageous from the viewpoint of not only starting characteristics but also speed reduction of the rotor in comparison with the Wells turbine.

\section{CONCLUSIONS}

The performances of the turbine with self-pitchcontrolled blades have been investigated by model testing and numerical simulation in oscillating flows. The results have been compared with those of Wells turbine. The conclusions are summarized as follows:

(1) A size of the hysteresis loop in turbine characteristics is smaller for the turbine presented here compared with that of Wells turbine.

(2) The quasi-steady analysis by use of the experimental data obtained from a steady flow condition is valid for this turbine.

(3) The present turbine is advantageous from the viewpoint of not only starting characteristics but also running characteristics and speed reduction of the rotor compared with Wells turbine. 


\section{NOMENCLATURE}

$b \quad=$ blade height

$C_{A}=$ input coefficient

$=\Delta p_{0} Q /\left\{\rho\left(v_{\mathrm{a}}^{2}+U_{R}^{2}\right) z b l v_{\mathrm{a}} / 2\right\}$

$C_{M}=$ moment coefficient

$C_{p}=$ pressure coefficient

$=\left(p-p_{1}\right) /\left\{\rho\left(v_{\mathrm{a}}^{2}+U_{R}^{2}\right) / 2\right\}$

$C_{T}=$ torque coefficient

$=T_{i} /\left\{\rho\left(v_{\mathrm{a}}^{2}+V_{\mathrm{a}}^{2}\right) z b l R / 2\right\}$

$f \quad=$ frequency of wave

$F=$ dimensionless output torque

$=T_{i} /\left(\pi \rho v_{\mathrm{a}}^{2} R^{3}\right)$

$I=$ moment of inertia of rotor

$l \quad=$ blade chord length

$M=$ pitching moment

$p \quad=$ static pressure on an airfoil

$p_{1}=$ free stream static pressure

$Q$ = flow rate

$R=$ mean radius

$S=$ dimensionless frequency

$t=$ time

$t^{*}=$ dimensionless time $=t f$

$T_{i}=$ output torque

$T_{\mathrm{L}}=$ loading torque

$U_{R}=$ tangential velocity at mean radius

$v_{\mathrm{a}}=$ mean axial velocity

$V_{\mathrm{a}}=$ maximum value of $v_{\mathrm{a}}$

$x=$ distance along blade chord

$X_{I}=$ dimensionless moment of inertia

$=I /\left(\pi \rho R^{5}\right)$

$X_{\mathrm{L}}=$ dimensionless loading torque

$=T_{\mathrm{L}} /\left(\pi \rho R^{3} v_{\mathrm{a}}^{2}\right)$ $y=$ distance perpendicular to blade chord

$z \quad=$ number of blades

$\alpha=$ angle of incidence

$\gamma \quad=$ setting angle

$\Delta p_{0}=$ total gauge pressure in air chamber

$\bar{\eta}=$ mean turbine efficiency

$\rho=$ density of air

$\omega=$ angular velocity

$\omega^{*}=$ dimensionless angular velocity $=\omega / f$

\section{Acknowledgments}

The Authors wish to acknowledge the financial support given by The British Council for these investigations.

\section{References}

Inoue, M., Kaneko, K., Setoguchi, T. and Hamakawa, H., 1989. Air turbine with self-pitch controlled blades for wave power generator, JSME Int. J., Ser. II, 32(1), 19-24.

Inoue, M., Kaneko, K., Setoguchi, T. and Raghunathan, S., 1986a. Simulation of starting characteristics of the Wells turbine, Proc. of AIAA/ASME 4TH Fluid Mech., Plasma Dyn. \& Lasers Conf., Paper No. AIAA-86-1122.

Inoue, M., Kaneko, K., Setoguchi, T. and Shimamoto, K., 1986b. Studies of Wells turbine for wave power generator, Bull. JSME, 29(250), 1177-1182.

Raghunathan, S., Setoguchi, T. and Kaneko, K., 1987. The Wells air turbine subjected to inlet flow distribution and high level of turbulence, Int. J. Heat \& Fluid Flow, 8(2), 165-167. Setoguchi, T., Kaneko, K., Hamakawa, H. and Inoue, M., 1990. Measurement of hysteresis on Wells turbine characteristics in reciprocating flow, Proc. of 1st Int. Symp. on Exp. and Comp. Aerothermodynamics of Internal Flows, pp. 537-543. 


\section{ait \\ ENERGY MATERIALS}

M A N E Y publishing

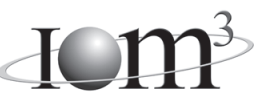

\section{Materials Science \& Engineering for Energy Systems}

Maney Publishing on behalf of the Institute of Materials, Minerals and Mining

The Institute of Materials, Minerals \& Mining

Economic and environmental factors are creating ever greater pressures for the efficient generation, transmission and use of energy. Materials developments are crucial to progress in all these areas: to innovation in design; to extending lifetime and maintenance intervals; and to successful operation in more demanding environments. Drawing together the broad community with interests in these areas, Energy Materials addresses materials needs in future energy generation, transmission, utilisation, conservation and storage. The journal covers thermal generation and gas turbines; renewable power (wind, wave, tidal, hydro, solar and geothermal); fuel cells (low and high temperature); materials issues relevant to biomass and biotechnology; nuclear power generation (fission and fusion); hydrogen generation and storage in the context of the 'hydrogen economy'; and the transmission and storage of the energy produced.

As well as publishing high-quality peer-reviewed research, Energy Materials promotes discussion of issues common to all sectors, through commissioned reviews and commentaries. The journal includes coverage of energy economics and policy, and broader social issues, since the political and legislative context influence research and investment decisions.

\section{CALL FOR PAPERS}

Contributions to the journal should be submitted online at http://ema.edmgr.com

To view the Notes for Contributors please visit: www.maney.co.uk/journals/notes/ema

Upon publication in 2006, this journal will be available via the Ingenta Connect journals service. To view free sample content online visit: www.ingentaconnect.com/content/maney

For further information please contact:

Maney Publishing UK

Tel: +44 (0)113 2497481 Fax: +44 (0)1132486983 Email: subscriptions@maney.co.uk

or

Maney Publishing North America

Tel (toll free): 8662975154 Fax: 6173546875 Email: maney@maneyusa.com

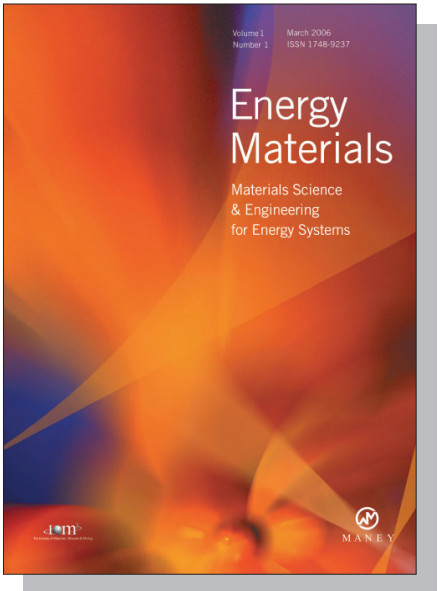

EDITORS

Dr Fujio Abe

NIMS, Japan

Dr John Hald, IPL-MPT, Technical University of Denmark, Denmark

Dr R Viswanathan, EPRI, USA

\section{SUBSCRIPTION INFORMATION}

Volume 1 (2006), 4 issues per year

Print ISSN: 1748-9237 Online ISSN: 1748-9245

Individual rate: $£ 76.00 / U S \$ 141.00$

Institutional rate: $£ 235.00 /$ US $\$ 435.00$

Online-only institutional rate: $£ 199.00 / U S \$ 367.00$

For special $\mathrm{IOM}^{3}$ member rates please email

subscriptions@maney.co.uk

\section{For further information or to subscribe online please visit www.maney.co.uk}



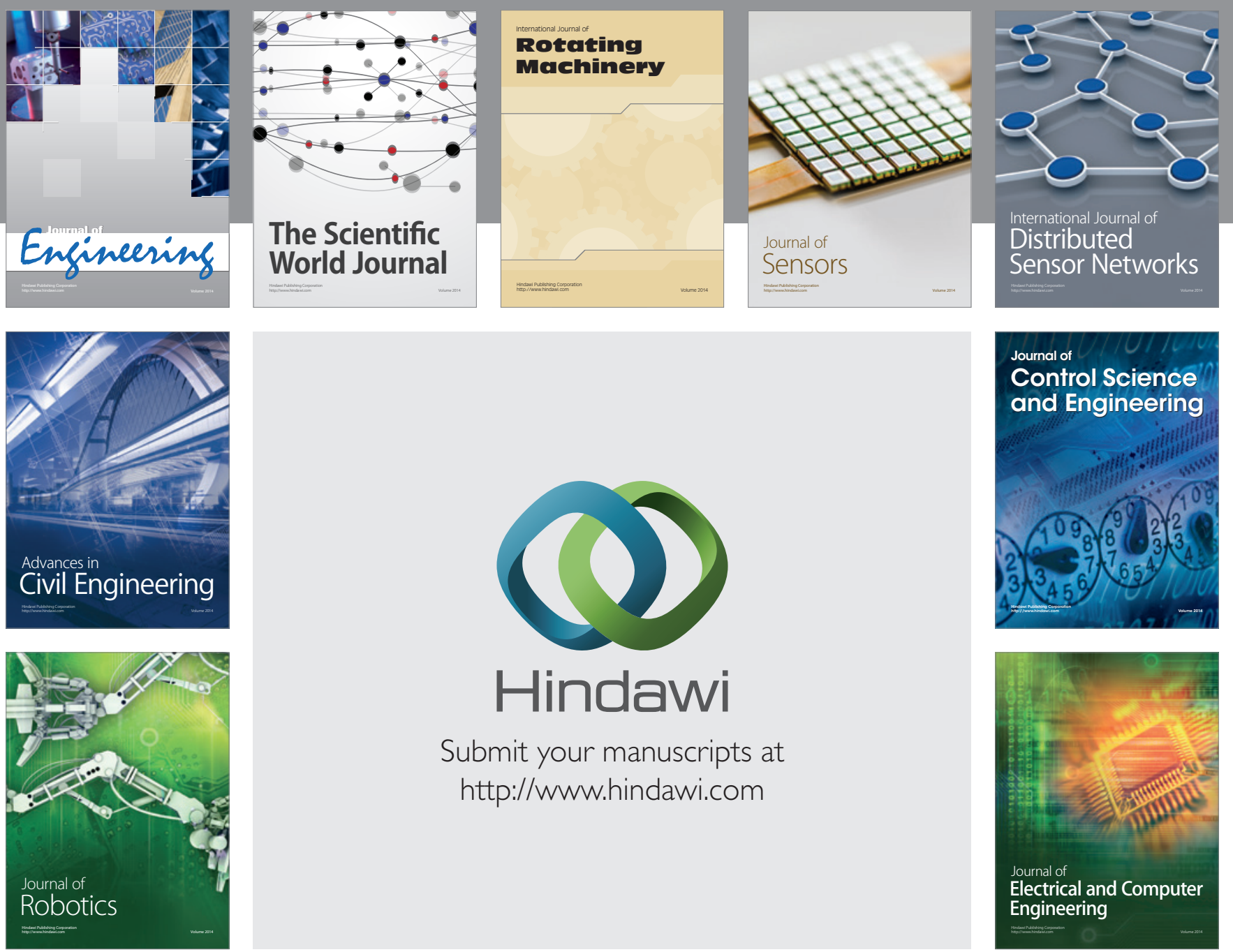

Submit your manuscripts at

http://www.hindawi.com
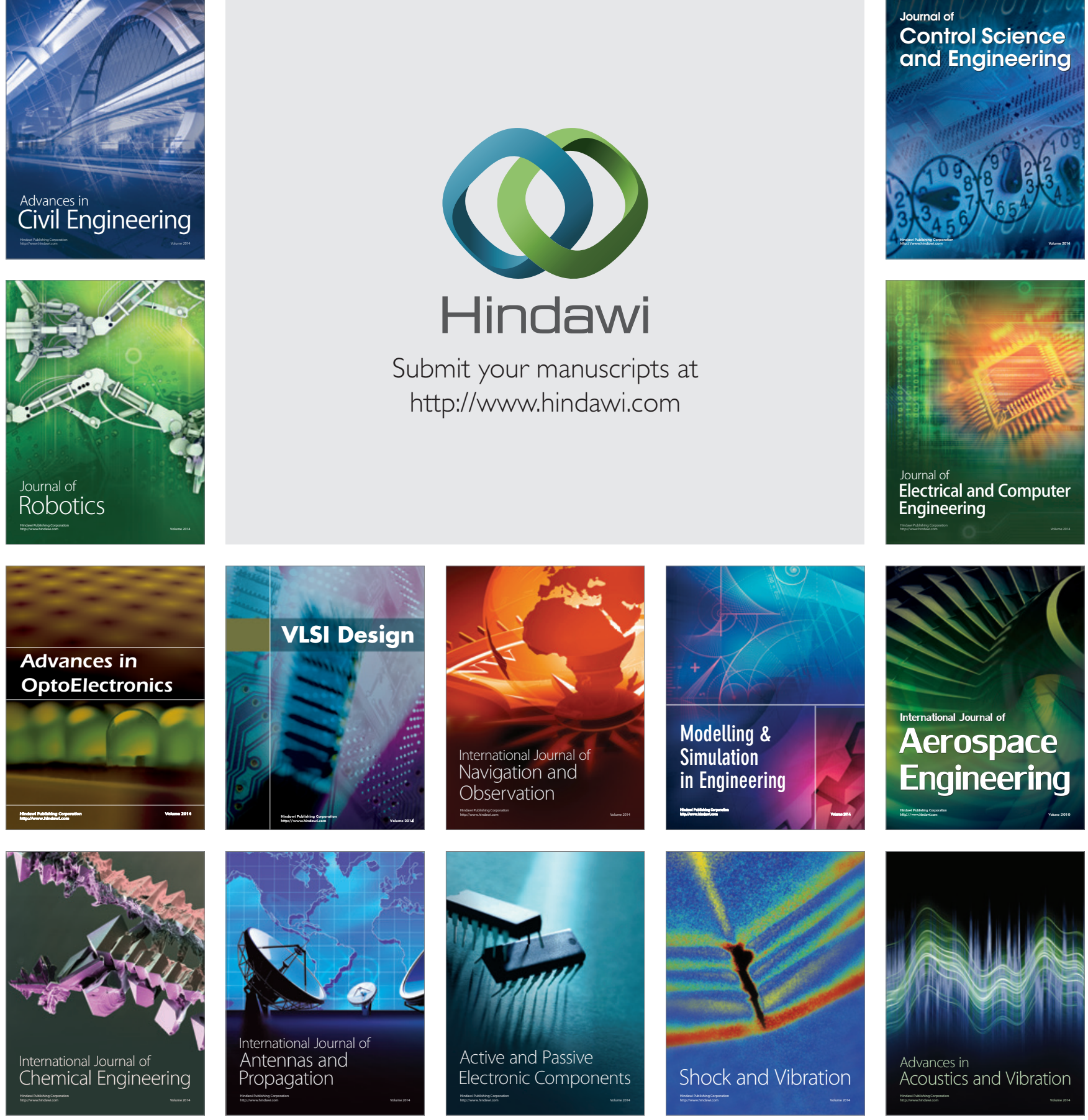